\title{
2||-|||||||||||||||||||||||||||||||||||||||||||||||||||||||||||||||||||.
}

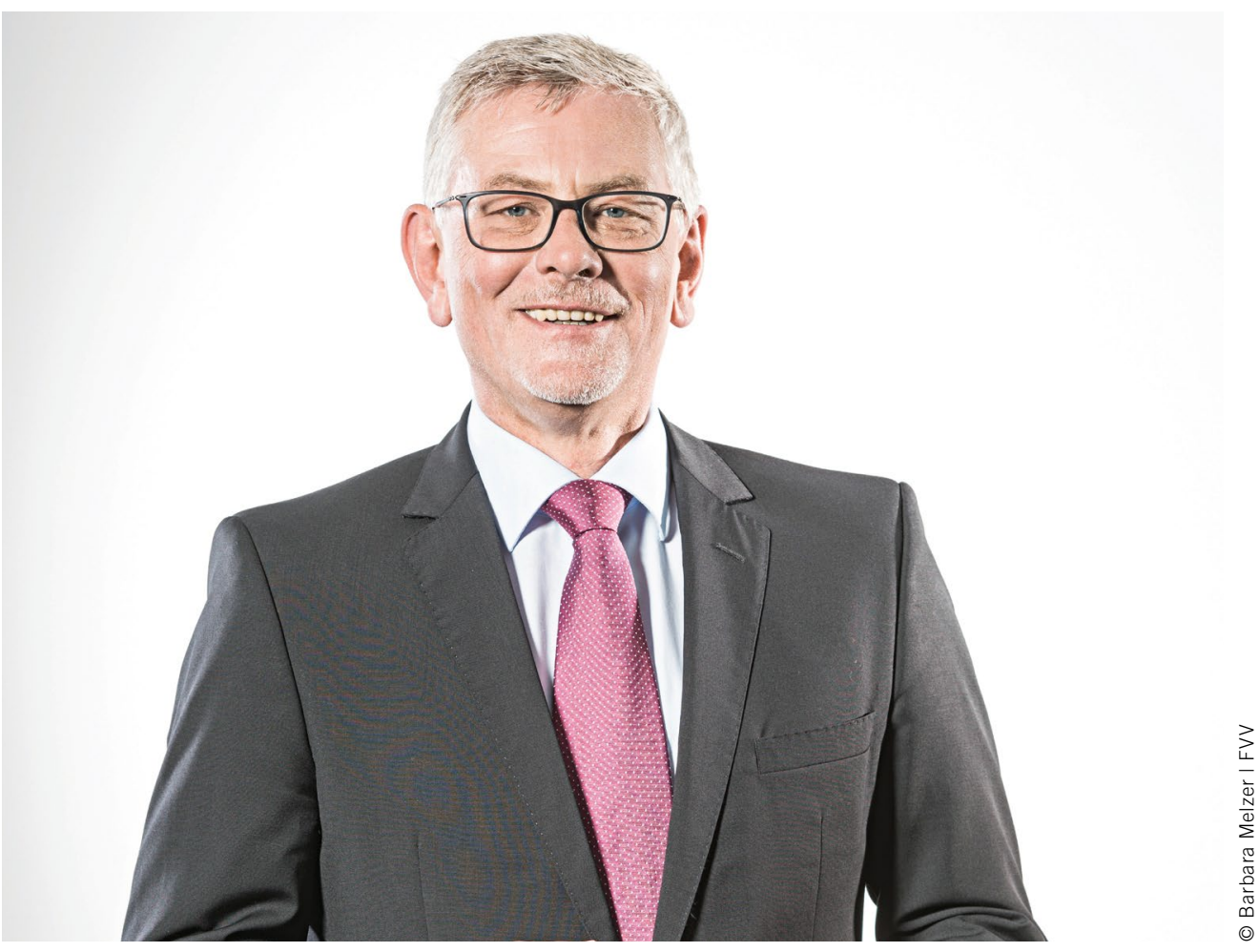

Dietmar Goericke

Geschäftsführer der

Forschungsvereinigung

Verbrennungskraftmaschinen

(FVV) e. V. in Frankfurt am Main

\section{Wasserstoff als Plattformtechnologie}

Was haben eine Erntemaschine im 24-h-Einsatz, ein Radlader auf einer städtischen Baustelle und ein 60-t-Lastzug für Holztransporte in Nordeuropa gemeinsam? Das Verbindende zwischen diesen unterschiedlichen Fahrzeugen ist heute der Dieselmotor, der nicht nur für die Antriebsleistung sorgt, sondern auch die Energie für die Arbeitsgeräte liefert. Von einem Kraftstoff angetrieben, dessen Basis fossiles Rohöl darstellt, war dieser Universalantrieb unschlagbar praktisch! Doch wenn wir es ernst meinen mit der Defossilisierung der gesamten Wirtschaft, dann gilt es, auch für den Gütertransport sowie alle mobilen Arbeitsmaschinen sowohl den Energiewandler als auch den Energieträger anzupassen. Gibt es dabei eine neue Universallösung für jeden Einsatzzweck?

Neben der Elektrifizierung mittels Batterie, die im HeavyDuty-Bereich schnell an Grenzen stößt, werden derzeit vor allem zwei mobile Energiewandler diskutiert: die Brennstoffzelle sowie die mit regenerativen Kraftstoffen betriebene Verbrennungskraftmaschine. Unter den regenerativen Kraftstoffen gibt es wiederum eine ganze Reihe vielversprechender Kandidaten. Es scheint schwer vorstellbar, dass in Zukunft ein einziger Energiewandler, betrieben mit einem einzigen Brenn- oder Kraftstoff, das Rennen macht. Wenn man jedoch die gesamte Energiekette betrachtet, also von der Windenergieanlage bis zum Rad, dann gibt es in nahezu allen Ansätzen eine Schnitt- menge: Wasserstoff. Er kann mit vergleichsweise geringen Verlusten großtechnisch aus regenerativ erzeugtem Strom hergestellt werden. Wasserstoff kann direkt im Fahrzeug genutzt oder mithilfe weitgehend bekannter Verfahren zu bekannten gasförmigen oder flüssigen Kraftstoffen weiterverarbeitet werden. Die Nummer eins im Periodensystem der Elemente stellt keine neue Universallösung dar. Aber sie ist in vielen Fällen die Plattform, auf der innovative, klimafreundliche Technologien aufsetzen. Voraussetzung dafür ist eine entsprechende politische Weichenstellung, vor allem eine ambitionierte Umsetzung der europäischen Richtlinie für erneuerbare Energien II (RED II) in nationale Gesetzgebung und Normung.

Was bedeutet das für die industrielle Gemeinschaftsforschung? Die FVV verfolgt einen dualen Ansatz: Einerseits definieren Unternehmen „bottom-up“ die Mehrzahl aller Projekte an der Schnittstelle von Energieträger zu Energiewandler. So sollen jene Hindernisse beseitigt werden, die einem wirtschaftlichen Einsatz wasserstoffbasierter Technologien noch entgegenstehen. Andererseits werden „top-down“ grundsätzliche Fragen untersucht, etwa zur Lebenszyklusanalyse einzelner Technologiepfade oder auch zur Wasserstoffinfrastruktur. Beide Ansätze sind zwingend notwendig. Denn auch wenn Wasserstoff als Plattformtechnologie zum Einsatz kommt: So einfach wie heute wird die Antriebswelt der Zukunft nie wieder! 